\title{
Needs According to the Problems of Mammography Education
}

\author{
Dong-Hee Hong, Hong-Ryang Jung, Cheong-Hwan Lim, Woo-Taek Lim, Young-Cheol Joo
}

\begin{abstract}
Mammography is a difficult technique, but there is no phantom for education. Therefore, we analyze the need and necessity to produce the phantom that meets the training needs. Data collection was performed by 199 independent radiological technologists in the breast and breast clinic of six hospitals except Jeju Island. The independent t-test and one-way ANOVA were conducted to determine the relationship between the demographic characteristics of the radiologist and the mothers' Duncan was used for statistical analysis.

There was no statistically significant difference in perception and attitude according to demographic and statistical characteristics. Attitudes and attitudes according to job characteristics were influenced only by working style, by mammography education, and by education need.

The results of the questionnaire showed that the education conditions of most mammography radiologists were difficult and the training of mammography was necessary.
\end{abstract}

Keywords : Clinical, Education, Mammography, Needs, Problems

\section{INTRODUCTION}

According to the lifestyle, the incidence of breast cancer is increasing and it is ranked as the first female cancer incidence in Korea [1]. Therefore, regular mammograms were performed, and the number of mammograms increased as well. Women 's hospitals conducting nationwide breast shots feel the necessity of taking breast - shots awareness more seriously considering the increased number of cases together with the check - up season every year.

In reality, mammography has both sides in which the radiation exposure is disturbed, which can cause the patient to suffer radiation damage and cause severe disability [2],[3]. Therefore, radiologists working in clinical practice should be careful not to be exposed to unnecessary radiation due to retaking.

The most useful thing for early detection of breast cancer is mammography. Mammography is a diagnostic method that

Revised Manuscript Received on September 25, 2019

Dong-Hee Hong, Dept. of Radiology Science, Shinhan University,11644, Republic of Korea. Email: hansound2@shinhan.ac.kr

Hong-Ryang Jung*, Dept. of Radiology Science, Hanseo University,31962, Republic of Korea. Email: hrjung@hanseo.ac.kr

Cheong-Hwan Lim, Dept. of Radiology Science, Hanseo University,31962, Republic of Korea. Email: lch116@hanseo.ac.kr

Woo-Taek Lim, Dept. of Radiology Science, Konkuk University Medical center,05030, Republic of Korea. y4769@nate.com

Young-Cheol Joo, Dept. of Radiology, Samsung Medical center,06351, Republic of Korea. skulljoo@naver.com can diagnose the shape and size of the mass, dilation of the mammary gland, fibrosis, and calcification.

Mammography is performed with a basic examination of the cranio-caudal (CC) and mediolateral-oblique (MLO) directions [4],[5],[6]. Therefore, it is considered that a process of knowing all the examination methods for mammography and performing a lot of practice in advance for various patients is necessary[7],[9],[10].

However, at present, there are not many schools that teach mammography during the regular course in the university. Even if they are established, only the theory about it is taught and accurate practice is not done. This is a sensitive area where practicum can be done, but there is not enough room for recognition and practical training.

The purpose of this study is to investigate and analyze the essential conditions and needs of mammography education which can find out the problems of mammography education and apply it directly to the clinic.

\section{MATERIALS AND METHODS}

\section{A. Objectives}

This study was a descriptive study to analyze the problems and needs of mammography education. We used the radiologist who works in the mammography room of the National Dental Hospital in Korea. From November 1, 2017 to December 30, 2017, a total of 202 questionnaires were distributed. A total of 199 copies (98.51\% recovery rate) were used as the analytical data except for the three insufficient responses and the non-response questionnaire in the collected questionnaires.

\section{B. Methods}

This study modifies and complements the structured questionnaire of Kim Jung Hoon [8], and consists of 7 items of demographic characteristics, 9 items of educational needs, 9 items of education needs, 11 items related to mammography and attitude, and 10 items of self - esteem A total of 37 items were composed. The self-esteem items related to the breast-shooting awareness and attitude except for the demographic characteristics, education, and educational needs items were Likert scale of 5 points $(1=$ highly agree, $2=$ yes, $3=$ moderate, $4=$ not) , $5=$ not very much) [8].

As shown in Table I, the Cronbach's alpha coefficient of the questionnaire used was 0.828 for breast image recognition and attitude, and 0.713 for self-esteem. 
Needs According to the Problems of Mammography Education

Table-I: Formation of survey to measure items

\begin{tabular}{|c|c|c|c|}
\hline Variables & & Items & $\alpha$ \\
\hline \multirow[t]{2}{*}{$\begin{array}{c}\text { Dependent } \\
\text { Variable }\end{array}$} & $\begin{array}{l}\text { Mammography } \\
\text { awareness and } \\
\text { attitudes }\end{array}$ & $\begin{array}{l}\text { The need for a } \\
\text { mammography phantom (6) } \\
\text { The usefulness for a } \\
\text { mammography phantom (3) } \\
\text { The need for a } \\
\text { mammography education (2) }\end{array}$ & 0.828 \\
\hline & Self-esteem & $\begin{array}{l}\text { Job confident }(5) \\
\text { Job depression }(5)\end{array}$ & 0.713 \\
\hline
\end{tabular}

\section{Statistic analysis}

The collected data were analyzed using SPSS 24.0 statistical package and frequency analysis was conducted to examine the demographic characteristics and educational needs of radiologists.

The independent t-test and one-way ANOVA were conducted to determine the relationship between the demographic characteristics of the radiologist and the mothers' Duncan was used for statistical analysis. The significance level was $95 \%$ ( 0.05 or less).

\section{RESULTS}

\section{A. General Characteristics of Breast Imaging Radiologists}

As shown in Table $\Pi$, the demographic characteristics of the radiologists participating in this study were $94.5 \%$ (188) in women and $5.5 \%$ (11) in men. The most common age group among the $20-29$ age group was $48.2 \%$ (96 persons), followed by $41.2 \%$ ( 82 persons) in the 30-39 age group and $10.6 \%$ (21 persons) $53.3 \%$ (106 persons) were married, and $46.7 \%$ (93 persons) were married. The final education level was followed by $57.3 \%$ (114 students), 34.7\% (69 students), and $8.0 \%$ (16 students). Radiation history was highest in $36.2 \%$ (72 patients), less than 5 years $(33.2 \%)$, more than 5 years $(20.6 \%)$, less than 1 year And $10.1 \%$ (20 persons), respectively. The number of working hospitals was the highest at $50.3 \%$ (100 persons) in general hospitals, followed by $23.6 \%$ (47 persons) in general hospitals, $19.6 \%$ (39 persons) in hospitals and 6.5\% (13 persons) in hospitals. Gyeonggi-do was the highest with $47.7 \%$ (95) in Seoul, followed by Gyeonggi-do with $20.6 \%$ (41), Gyeongsang-do with $14.6 \%$ (29), Chungcheong province with $7.0 \%$ with 14 , Cholla province with $6.0 \% 8$ ).

Table-II : General characteristics of the radiotechnologist in mammography room

\begin{tabular}{l|l|l|l}
\hline \hline Characteristics & Categories & $\mathbf{N}$ & $\%$ \\
\hline \hline \multirow{2}{*}{ Gender } & Male & 11 & 5.5 \\
\cline { 2 - 4 } & Female & 188 & 94.5 \\
\hline \multirow{3}{*}{ Age(yrs) } & $20 \sim 29$ & 96 & 48.2 \\
\cline { 2 - 4 } & $30 \sim 39$ & 82 & 41.2 \\
\hline
\end{tabular}

\begin{tabular}{|c|c|c|c|}
\hline & $\geq 40$ & 21 & 10.6 \\
\hline \multirow{2}{*}{ Marriage } & Married & 93 & 46.7 \\
\hline & Single & 106 & 53.3 \\
\hline \multirow{3}{*}{ Final education } & Technical college & 69 & 34.7 \\
\hline & College & 114 & 57.3 \\
\hline & Master & 16 & 8.0 \\
\hline \multirow{4}{*}{ Career(yrs) } & $<1$ & 20 & 10.1 \\
\hline & $1 \sim 5$ & 72 & 36.2 \\
\hline & $5 \sim 10$ & 41 & 20.6 \\
\hline & $>10$ & 66 & 33.2 \\
\hline \multirow{4}{*}{ Hospital scale } & clinic & 39 & 19.6 \\
\hline & hospital & 13 & 6.5 \\
\hline & general Hospital & 47 & 23.6 \\
\hline & Advanced General Hospital & 100 & 50.3 \\
\hline \multirow{6}{*}{ Working area } & Seoul & 95 & 47.7 \\
\hline & Gyeonggi-do & 41 & 20.6 \\
\hline & Chungcheong-do & 14 & 7.0 \\
\hline & Gyungsang-do & 29 & 14.6 \\
\hline & Jeolla-do & 12 & 6.0 \\
\hline & Gangwon-do & 8 & 4.0 \\
\hline
\end{tabular}

\section{B. Job Characteristics of the radiotechnologist in mammography room}

Table II shows the frequency analysis of the job characteristics of the radiologists working in the mammography room. The average number of working hours was $75.4 \%$ ( 150 persons) for 8 hours, $19.1 \%$ (38 persons) for workers who worked more than 8 hours, and $5.5 \%$ (11) for workers who worked less than 8 hours. In the working hours, the wearing of the radiation dosimeter was the highest at $77.4 \%$ ( 154 persons) at all times, $14.1 \%$ (28 persons) were wearing most of them, 6.0\% (12 persons) And 2.5\% (5 persons) did not. The most common reason for not wearing was the risk of loss of work $(58.8 \%, 10$ persons), and it was the same with $17.6 \%$ ( 3 persons) And 5.9\% (1 person) was the least, because it would be disadvantageous due to overexposure. The most frequent cause of breast cancer was $38.7 \%$ (77 patients), 33.7\% (67 patients), almost 15.1\% (30 patients), slightly more $12.1 \%$ (24 patients) (1 person) in the order of the most or less common. 69.3\% (138 persons) knew the measurement result of personal exposure dosimeter, and $30.7 \%$ (61 persons) did not know it. The actual results of quarterly measurements were 0.01 to $1.0 \mathrm{mSv}$ in $60.8 \%$ (121 patients), 1.1 to $2.0 \mathrm{mSv}$ in $10.6 \%$ (21 patients), 2.1 to 3.0 $\mathrm{mSv}, 3.1$ to $4.0 \mathrm{mSv}, \%$ (1 person).

There were $35.2 \%$ (70 patients) of hands and feet, $30.2 \%$ (60 patients) of thyroid gland, $22.1 \%$ (44 patients) of eyes, $6.5 \%$ (13 patients) of gonads and $6.0 \% 12$ ) in order. $86.9 \%$ (173) of them answered that they were not dedicated to mammography, and $13.1 \%$ (26) said that most of them were doing mammography and other photography. Of the total radiological history, $49.7 \%$ (99 patients) had the experience of 
performing mammography in the first to fifth years, $23.6 \%$

$10.6 \%$ (21 persons) for more than 10 years.

(47 patients) in less than 1 year, $16.1 \%$ (32 patients) And

Table-III : Job characteristics of the radiotechnologist in mammography room

\begin{tabular}{|c|c|c|c|}
\hline Characteristics & Categories & $\mathbf{N}$ & $\%$ \\
\hline \multirow{3}{*}{ Business hours } & $<8$ & 11 & 5.5 \\
\hline & 8 & 150 & 75.4 \\
\hline & $>8$ & 38 & 19.1 \\
\hline \multirow{4}{*}{$\begin{array}{l}\text { Wear an exposure } \\
\text { dosimeter }\end{array}$} & I do not wear it at all & 5 & 2.5 \\
\hline & I do not wear it & 12 & 6.0 \\
\hline & It's mostly worn & 28 & 14.1 \\
\hline & Always wear & 154 & 77.4 \\
\hline \multirow{4}{*}{$\begin{array}{l}\text { Why does not wear a } \\
\text { dosimeter exposure }\end{array}$} & It hurts my business and it's annoying & 3 & 17.6 \\
\hline & There should be no effect on radiation exposure & 3 & 17.6 \\
\hline & Overexposed will be penalized & 1 & 5.9 \\
\hline & There is a risk of loss during work & 10 & 58.8 \\
\hline \multirow{5}{*}{ Exposure feel } & Few & 30 & 15.1 \\
\hline & Little & 77 & 38.7 \\
\hline & Is average & 67 & 33.7 \\
\hline & A little more & 24 & 12.1 \\
\hline & A lot & 1 & 0.5 \\
\hline \multirow{6}{*}{$\begin{array}{l}\text { Exposure dose } \\
(\mathrm{mSv})\end{array}$} & I do not know & 54 & 27.1 \\
\hline & $0.01 \sim 1.0$ & 121 & 60.8 \\
\hline & $1.1 \sim 2.0$ & 21 & 10.6 \\
\hline & $2.1 \sim 3.0$ & 1 & 0.5 \\
\hline & $3.1 \sim 4.0$ & 1 & 0.5 \\
\hline & $4.1<$ & 1 & 0.5 \\
\hline \multirow{5}{*}{ Area of exposure } & Eye & 44 & 22.1 \\
\hline & Thyroid & 60 & 30.2 \\
\hline & Gonad & 13 & 6.5 \\
\hline & Hand \& Foot & 70 & 35.2 \\
\hline & etc. & 12 & 6.0 \\
\hline \multirow{2}{*}{ Only mammography } & Yes & 26 & 13.1 \\
\hline & No & 173 & 86.9 \\
\hline \multirow{4}{*}{ Mammography Career(yrs) } & $<1$ & 47 & 23.6 \\
\hline & $1 \sim 5$ & 99 & 49.7 \\
\hline & $5 \sim 10$ & 32 & 16.1 \\
\hline & $>10$ & 21 & 10.6 \\
\hline
\end{tabular}

C. Recognition and attitude toward mammography education and phantom necessity according to the general characteristics of breast radiologists

As shown in table IV, as a result of studying the awareness and attitude toward breast imaging education and phantom necessity according to the demographic characteristics of the radiologists working in the mammography room, statistical analysis was conducted using statistical methods such as sex, age, marital status, career, $(\mathrm{P}<0.05)$. The marital status was $3.82 \pm 0.47$ (93 persons), $3.98 \pm 0.52$ (16 persons), and 3.98 $\pm 0.473 .83 \pm 0.49$ (20 persons), hospital size $3.86 \pm 0.43$ (13 persons), and work area $3.88 \pm 0.40$ ( 8 persons $)$ were the highest. 
Table-IV : Differences in cognition, attitude according to general characteristics
Table-V : Differences in self-esteem according to general characteristics

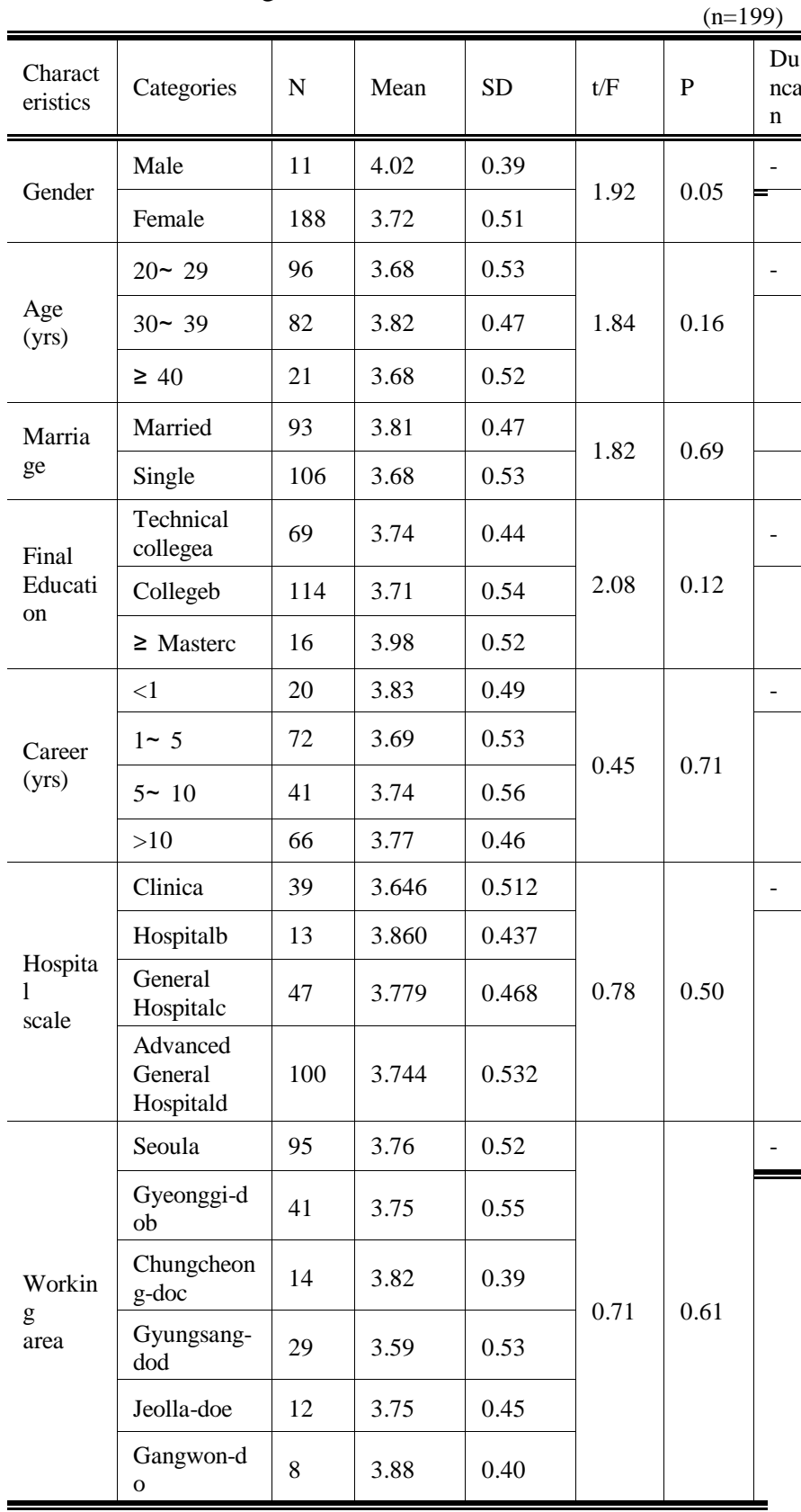

t; Duncan's post hoc analysis did not reveal any significant differences between groups.

D. Recognition and attitude toward mammography education and phantom necessity according to job characteristics of breast radiographers

As shown in table $\mathrm{V}$, as a result of studying the awareness and attitude about mammography training and phantom necessity according to the job characteristics of the radiologists working in the mammography room, it was found that the working style $(\mathrm{p}<0.05)$ affected the recognition and attitude, And $3.77 \pm 0.52$ (173), respectively, which were statistically significant. $3.76 \pm 0.41$ (17), $3.87 \pm$ 0.46 (13), $3.80 \pm 0.46,3.80 \pm 0.46$, and $3.80 \pm 0.36$, respectively. 0.57 (21) were the highest.

\begin{tabular}{|c|c|c|c|c|c|c|c|}
\hline $\begin{array}{l}\text { Characterist } \\
\text { ics }\end{array}$ & $\begin{array}{l}\text { Categor } \\
\text { ies }\end{array}$ & $\mathrm{N}$ & Mean & SD & $\mathrm{t} / \mathrm{F}$ & $\mathrm{P}$ & $\begin{array}{l}\mathrm{Du} \\
\mathrm{nca} \\
\mathrm{n}\end{array}$ \\
\hline \multirow{3}{*}{$\begin{array}{l}\text { Business } \\
\text { hours }\end{array}$} & $<8$ & 11 & 3.80 & 0.36 & \multirow{3}{*}{0.11} & \multirow{3}{*}{0.88} & \multirow{3}{*}{-} \\
\hline & 8 & 150 & 3.74 & 0.51 & & & \\
\hline & $>8$ & 38 & 3.72 & 0.56 & & & \\
\hline \multirow{2}{*}{$\begin{array}{l}\text { Wear an } \\
\text { exposure } \\
\text { dosimeter }\end{array}$} & Yes & 17 & 3.74 & 0.41 & \multirow{2}{*}{0.02} & \multirow{2}{*}{0.98} & \multirow{2}{*}{-} \\
\hline & No & 182 & 3.74 & 0.52 & & & \\
\hline \multirow{3}{*}{$\begin{array}{l}\text { Exposure } \\
\text { feel }\end{array}$} & Little & 107 & 3.76 & 0.48 & \multirow{3}{*}{0.24} & \multirow{3}{*}{0.78} & \multirow{3}{*}{-} \\
\hline & $\begin{array}{l}\text { Is } \\
\text { average }\end{array}$ & 67 & 3.71 & 0.49 & & & \\
\hline & A lot & 25 & 3.73 & 0.66 & & & \\
\hline \multirow{5}{*}{$\begin{array}{l}\text { Area of } \\
\text { exposure }\end{array}$} & Eye & 44 & 3.82 & 0.50 & \multirow{5}{*}{1.83} & \multirow{5}{*}{0.12} & \multirow{5}{*}{-} \\
\hline & Thyroid & 60 & 3.79 & 0.45 & & & \\
\hline & Gonad & 13 & 3.87 & 0.46 & & & \\
\hline & $\begin{array}{l}\text { Hand \& } \\
\text { Foot }\end{array}$ & 70 & 3.66 & 0.57 & & & \\
\hline & etc. & 12 & 3.48 & 0.39 & & & \\
\hline \multirow{2}{*}{$\begin{array}{l}\text { Only } \\
\text { mammograp } \\
\text { hy }\end{array}$} & Yes & 26 & 3.53 & 0.33 & \multirow{2}{*}{-2.31} & \multirow{2}{*}{0.02} & \multirow{2}{*}{-} \\
\hline & No & 173 & 3.77 & 0.52 & & & \\
\hline \multirow{4}{*}{$\begin{array}{l}\text { Mammogra } \\
\text { phy Career } \\
\text { (yrs) }\end{array}$} & $<1$ & 47 & 3.82 & 0.50 & \multirow{4}{*}{0.814} & \multirow{4}{*}{0.48} & \multirow{4}{*}{-} \\
\hline & $1 \sim 5$ & 99 & 3.69 & 0.51 & & & \\
\hline & $5 \sim 10$ & 32 & 3.75 & 0.47 & & & \\
\hline & $>10$ & 21 & 3.80 & 0.57 & & & \\
\hline
\end{tabular}

\section{E. Awareness and Attitude of Breast Imaging Education} and Phantom Necessity according to Breast Imaging Education Needs and Educational Needs of Breast Imaging Radiologists

As shown in table VI, as a result of studying the awareness and attitude about mammography training and phantom necessity according to whether breast radiographers were working in the mammography room and education needs, it was found that the breast radiograph training $(\mathrm{p}<0.05)$. In the college, breast aesthetics were $3.81 \pm 0.48$ (177), the highest, and statistically significant. $3.77 \pm 0.52$ (170 person), $3.82 \pm 0.59$ (78 person), $3.86 \pm 0.55$ ( 58 person), and $3.86 \pm 0.55$ (58 person) $3.89 \pm 0.59$ (19 person, $3.74 \pm 0.52$ (185 person), and $3.92 \pm 0.54$ ( 24 person), respectively

Table-VI : Differences in cognition, attitude according to job characteristics

\begin{tabular}{l|l|l|l|l|l|l|l}
\hline \hline $\begin{array}{l}\text { Character } \\
\text { istics }\end{array}$ & $\begin{array}{l}\text { Categorie } \\
\mathrm{s}\end{array}$ & $\mathrm{N}$ & Mean & $\mathrm{SD}$ & $\mathrm{t} / \mathrm{F}$ & $\mathrm{P}$ & $\begin{array}{l}\text { Du } \\
\mathrm{nc} \\
\mathrm{an}\end{array}$ \\
\hline \hline Education & Yes & 170 & 3.77 & 0.52 & 1.78 & 0.07 & - \\
\hline
\end{tabular}




\begin{tabular}{|c|c|c|c|c|c|c|c|}
\hline $\begin{array}{l}\text { al } \\
\text { Experienc } \\
\text { e }\end{array}$ & No & 29 & 3.59 & 0.41 & & & \\
\hline \multirow{3}{*}{$\begin{array}{l}\text { Education } \\
\text { al Format }\end{array}$} & $\begin{array}{l}\text { Only } \\
\text { theory }\end{array}$ & 63 & 3.77 & 0.43 & \multirow{3}{*}{1.52} & \multirow{3}{*}{0.22} & \multirow{3}{*}{ - } \\
\hline & $\begin{array}{l}\text { Only } \\
\text { practice }\end{array}$ & 29 & 3.62 & 0.47 & & & \\
\hline & $\begin{array}{l}\text { Theory } \\
\text { and } \\
\text { practice }\end{array}$ & 78 & 3.82 & 0.59 & & & \\
\hline \multirow{2}{*}{$\begin{array}{l}\text { Phantom } \\
\text { Experienc } \\
\text { e }\end{array}$} & Yes & 58 & 3.86 & 0.55 & \multirow{2}{*}{1.67} & \multirow{2}{*}{0.09} & \multirow{2}{*}{ - } \\
\hline & No & 112 & 3.72 & 0.50 & & & \\
\hline \multirow{3}{*}{$\begin{array}{l}\text { Phantom } \\
\text { Inconveni } \\
\text { ence }\end{array}$} & Not soft & 19 & 3.89 & 0.59 & \multirow{3}{*}{1.21} & \multirow{3}{*}{0.30} & \multirow{3}{*}{-} \\
\hline & $\begin{array}{l}\text { Different } \\
\text { from } \\
\text { human } \\
\text { body }\end{array}$ & 68 & 3.75 & 0.52 & & & \\
\hline & $\begin{array}{l}\text { Discomfo } \\
\mathrm{rt} \text { of } \\
\text { anatomy }\end{array}$ & 23 & 3.83 & 0.42 & & & \\
\hline \multirow{2}{*}{$\begin{array}{l}\text { Use } \\
\text { phantom } \\
\text { outside }\end{array}$} & Yes & 14 & 3.77 & 0.36 & \multirow{2}{*}{0.19} & \multirow{2}{*}{0.84} & \multirow{2}{*}{ - } \\
\hline & No & 185 & 3.74 & 0.52 & & & \\
\hline \multirow{2}{*}{$\begin{array}{l}\text { College of } \\
\text { mammograp } \\
\text { hy }\end{array}$} & Yes & 177 & 3.81 & 0.48 & \multirow{2}{*}{5.82} & \multirow{2}{*}{$<0.00$} & \multirow{2}{*}{ - } \\
\hline & No & 22 & 3.19 & 0.35 & & & \\
\hline \multirow{4}{*}{$\begin{array}{l}\text { College of } \\
\text { mammogr } \\
\text { aphy }\end{array}$} & Not & 38 & 3.67 & 0.51 & \multirow{4}{*}{1.48} & \multirow{4}{*}{0.22} & \multirow{4}{*}{-} \\
\hline & 1 & 24 & 3.92 & 0.54 & & & \\
\hline & $2 \sim 3$ & 80 & 3.76 & 0.51 & & & \\
\hline & $>4$ & 57 & 3.69 & 0.48 & & & \\
\hline
\end{tabular}

$\dagger$; Duncan's post hoc analysis did not reveal any significant differences between groups.

\section{DISCUSSION}

This study was conducted to investigate the perception, attitude, and self-esteem of breast cancer surgeons working in the mammography department. And the number of radiation education was not analyzed. As the knowledge level and attitude were significantly influenced by the regularly educated group, the number of radiation education mammography room were investigated And to present basic data for making mammography phantom[11].

\section{CONCLUSION}

This study was conducted to investigate the current state of awareness and attitude according to mammography training and phantom necessity of radiologists working in the mammography room. Factors influencing demographics, job characteristics, and educational needs were analyzed.

First, perceptions and attitudes according to demographic and statistical characteristics were not statistically significant.

Second, radiation protection according to job characteristics influenced recognition and attitude, and statistically significant.

Third, the perception and attitude according to breast education education needs and education needs were influenced only by receiving breast training at university and statistically significant.

\section{ACKNOWLEDGMENT}

This work was supported by the National Research Foundation of Korea (NRF) grant (No. NRF-2017R1C1B5017119) funded by the Korea government (MSIP).

\section{REFERENCES}

1. J.M. Yang JM. Public Health Lecture, Seoul, 167, 1992.

2. H. R. Jung, "A Research Study on the Education System for Radiological Technologists and the Public health policy", Journal of radiological science and technology, vol. 27(4), 2004, pp. 67-74

3. H.S. Kim, A Study on the Satisfaction degree for Clinical Practics of Radiotechnology Students, Journal of radiological science and technology, vol. 27(4), 2004, pp. 75-83

4. E.O. Han "Survey and study on the safety management of radiation: centering on the radiation workers in medical institutions", Department of Health Education The Graduate School of Ewha Womans University, 2002.

5. S.G. Kang. "Knowledge on Radiation Protection, Recognition and Performance on Radiation Protective Behavior in Operating Room Nurse", Department of Nursing Graduate School, Dong-A University, 2012.

6. H.C. Cho. "Study on perception and behavior about radiation safety management and measurement of radiation dose for workers who work in the angiography room", Department of Environment and Occupational Health Graduate School of Public Health Korea University, 2004.

7. Food and Drug Administration. Guideline for reducing radiation dose of patients, 2011

8. J.H Kim, S.J. Ko, S.S Kang, S.Y. Choi, C. S. Kim. "Analysis of Radiation/ Radioactivity-Related Knowledge, Perception and Behaviors of Radiological Technologists", Journal of Radiological Science and Technology, vol.34(2),2011, pp.123-129

9. H.S. Kim. "Knowledge, awareness and awareness of radiological Behavior Research", Yonsei University Graduate School of Public Health Graduate Thesis, 2001.

10. G.E. Jeon. "Survey of Radiation Workers' Knowledge, Perception, and Behavior for Radiation", Department of Public Health Graduate School of Chonnam National University, 2013.

11. G.N. Choi, G.S. Jeon, Y.W. Kim. "Radiation Exposure Dose on Persons Engaged in Radiation-related industries", Journal of the Korean Society of Radiology, vol. 6(1), 2012, pp. 27-37

\section{AUTHORS PROFILE}

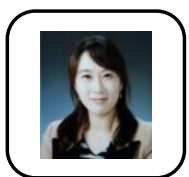

Dong-Hee Hong is currently a professor of departmen of radiological science at Shinhan University in Republic of Korea. She holds a master's degree in radiology and a doctorate in Health education from Hanseo University in Republic of Korea.

His main research area is mammography, and many SCOPUS and KCI journals related to mammography have been published.

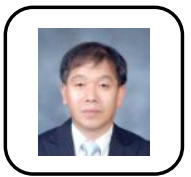

Hong-Ryang Jung received a Ph.D. degree in public health at Soonchunhyang University in 2003. He is currently a professor of radiological science at Hanseo University in South Korea. His research is mainly about environmental radiation and medical radiation dose.

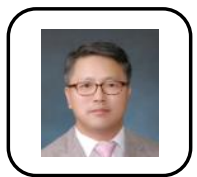

Cheong-Hwan Lim Professor of department of radiological science and health medicine at Hanseo University in Republic of Korea (2001 currently).

Currently serving as chairman of the Korea Radiological Science Association and chairman of the editorial committee (2016 currently). 
Woo-Taek Lim is currently working at department of Radiology, Konkuk University Medical Center in republic of Korea, as a radiological technologist.

He received Master of Urban and Regional Planning in Public Administration from Konkuk University, Korea, in 2012. In 2017, he obtained Ph.D. in health science from Hanseo University, Korea. Research interest includes development of new
radiographic technique and quality management of MR image. Having 10 publications in SCOPUS journals, 1 publication KCI journal.

Young-Cheol Joo is currently working at department of Radiology, Samsung Medical Center in republic of Korea, as a radiological technologist. He holds a master's degree in radiology and a doctorate in Health education from Hanseo University in Republic of Korea.

Research interest includes development of new radiographic technique method of radiography and reduction method of radiation dose on radiography for patient. Having 1 Publications in SCIE Journal, 4 publications Scopus Journals and 10 KCI Journals. 